\title{
Fixed Point Theorems for Two Weakly Increasing Mappings by Using Delbosco's Set in Ordered G-Metric Spaces
}

\author{
${ }^{1}$ P. L. Sanodia, ${ }^{2}$ Arvind Gupta, ${ }^{3}$ Amit Kumar Pandey \\ ${ }^{l}$ Deptt.of Mathematics Institute for Excellence in Higher Education, Bhopal M.P. India \\ ${ }^{2}$ Deptt.of Mathematics Govt. Motilal Vigyan Mahavidhyalaya, Bhopal M.P. India \\ ${ }^{3}$ Department of Mathematics, RKDF Institute of Science \& Technology, Bhopal, Pin-462026, M.P., India
}

Abstract: We give some fixed point theorems for two weakly increasing self-mappings $T$ and $S$ satisfying contractive type conditions by using Delbosco's set in ordered G-metric spaces.

2000 AMS Mathematics subject classification: 47H10, 54H25.

Keywords and Phrases: Delbosco's set, contraction, weakly increasing mappings, fixed point, ordered G-metric spaces.

\section{Introduction}

In [1], to give a unified approach for contraction mappings D. Delbosco's considered the set $\mathcal{F}$ of all continuous function $\mathrm{g}:[0,+\infty)^{3} \rightarrow[0,+\infty)$ satisfying the following conditions:

$$
\begin{aligned}
& (\mathrm{g}-1) \quad: \mathrm{g}(1,1,1)=\mathrm{h}<1, \\
& (\mathrm{~g}-2) \quad: \text { If } \mathrm{u}, \mathrm{v} \in[0,+\infty) \text { are such that } \\
& \mathrm{u} \leq \mathrm{g}(\mathrm{u}, \mathrm{v}, \mathrm{v}) \text { oru } \leq \mathrm{g}(\mathrm{v}, \mathrm{u}, \mathrm{v}) \text { or } \mathrm{u} \leq \mathrm{g}(\mathrm{v}, \mathrm{v}, \mathrm{u})
\end{aligned}
$$

And proved the following.

Theorem: 1.1 (see [1]) Let(X, d) be a complete metric space. If $\mathrm{S}$ and $\mathrm{T}$ are two mappings from $\mathrm{X}$ into itself, satisfying the following conditions:
$(1.1)$

$$
d(S x, T y) \leq g(d(x, y), d(x, S x), d(y, T y))
$$

for all $\mathrm{x}, \mathrm{y} \in \mathrm{X}$. where, $\mathrm{g} \in \mathcal{F}$. Then $\mathrm{S}$ and $\mathrm{T}$ have a unique common fixed point in $\mathrm{X}$.

Some authors proved many kinds of fixed point theorems for contractive type mappings by using Delbosco's set. (see [2-4]).The basic topological properties of ordered sets were discussed by Wolk [5] and Manjardet [6]. The existence of fixed point in partially ordered metric spaces was considered by Ran and Reurings [7]. The notion of G-metric space was introduced by Mustafa and Sims [8] as a generalization of the notion of metric spaces. Mustafa et al. studied many fixed point results in G-metric space [9-13].

\section{Basic Concepts}

In this section, we present the necessary definitions and theorems in G-metric spaces.

Throughout this paper, we will adopt the following notations: $\mathbb{N}$ is the set of all natural numbers, $\mathbb{R}^{+}$is the set of all non-negative real numbers. Consistent with Mustafa and Sims [8], the following definitions and results will be needed in the sequel.

Definition 2.1 (see [8])let $\mathrm{X}$ is a nonempty set and $\mathrm{G}: \mathrm{X} \times \mathrm{X} \times \mathrm{X} \rightarrow \mathbb{R}^{+}$be a function satisfying the following properties:

[G1] $\quad G(x . y, z)=0$ if $x=y=z$.

[G2] $0<\mathrm{G}(\mathrm{x}, \mathrm{x}, \mathrm{y})$, for all $\mathrm{x}, \mathrm{y} \in \mathrm{X}$ with $\mathrm{x} \neq \mathrm{y}$.

[G3] $G(x, x, y) \leq G(x, y, z)$, for all $x, y, z \in X$ with $z \neq y$.

[G4] $\quad G(x, y, z)=G(x, z, y)=G(y, z, x)=\cdots \ldots \ldots$ Symmetry in all three variables.

[G5] $\quad G(x, y, z) \leq G(x, a, a)+G(a, y, z)$ for all $x, y, z, a \in X$ (Rectangle inequality)

Then the function $\mathrm{G}$ is called a generalized metric or more specifically a G-metric on $\mathrm{X}$ and pair $(\mathrm{X}, \mathrm{G})$ is called a G-metric space.

Definition 2.2(see [8])Let $(X, G)$ be a G-metric space, and let $\left\{x_{n}\right\}$ be a sequence of points of $X$, a point $x \in X$ is said to be the limit of the sequence $\left\{x_{n}\right\}$, if $\lim _{n, m \rightarrow+\infty} G\left(x_{n}, x_{m}, x_{m}\right)=0$, and we say that the sequence $\left\{x_{n}\right\}$ is G-convergent to $\mathrm{x}$.Thus $\mathrm{x}_{\mathrm{n}} \rightarrow \mathrm{x}$ in a G-metric space $(\mathrm{X}, \mathrm{G})$ if for any $\varepsilon>0$, there exists $\mathrm{k} \in \mathrm{N}$ such that $\mathrm{G}\left(\mathrm{x}, \mathrm{x}_{\mathrm{n}}, \mathrm{x}_{\mathrm{m}}\right)<\varepsilon$ for all $\mathrm{m}, \mathrm{n} \geq \mathrm{k}$.

Proposition: 2.1(see [8]) Let(X, G) be a G-metric space. Then the following are equivalent:

(1). $\left\{\mathrm{x}_{\mathrm{n}}\right\}$ is G-convergent to;

(2). $\mathrm{G}\left(\mathrm{x}_{\mathrm{n}}, \mathrm{x}_{\mathrm{n}}, \mathrm{x}\right) \rightarrow 0$ asn $\rightarrow \infty$; 
(3). $\mathrm{G}\left(\mathrm{x}_{\mathrm{n}}, \mathrm{x}, \mathrm{x}\right) \rightarrow 0$ asn $\rightarrow \infty$;

(4). $G\left(x_{n}, x_{m}, x\right) \rightarrow 0$ asn, $m \rightarrow \infty$.

Definition: 2.3 (see [8]) Let $(X, G)$ be a G-metric space, a sequence $\left\{x_{n}\right\}$ is called G-Cauchy if for $\varepsilon>0$, there isk $\in \mathbb{N}$ such that $G\left(x_{n}, x_{m}, x_{l}\right)<\varepsilon$ for alln, $m, l \geq k$, that is $G\left(x_{n}, x_{m}, x_{l}\right) \rightarrow 0$ as $n, m, l \rightarrow+\infty$.

Proposition: 2.2(see [8]) Let $(X, G)$ be a G-metric space. Then the following are equivalent:

(1) The sequence $\left\{x_{n}\right\}$ is G-Cauchy;

(2) For every $\varepsilon>0$, there isk $\in \mathbb{N}$ such that $G\left(x_{n}, x_{m}, x_{m}\right)<\varepsilon$ for all $n, m \geq k$.

Definition: 2.4(see [8])Let $(X, G)$ and $\left(X^{\prime}, G^{\prime}\right)$ be $G$-metric spaces, and letT: $(X, G) \rightarrow\left(X^{\prime}, G^{\prime}\right)$ be a function. Then $\mathrm{T}$ is said to be $\mathrm{G}$-continuous at a point $\mathrm{a} \in \mathrm{X}$ if and only if for every $\varepsilon>0$, there is $\delta>0$ such that $\mathrm{X}, \mathrm{y} \in \mathrm{X}$ and $\mathrm{G}(\mathrm{a}, \mathrm{x}, \mathrm{y})<\delta$ implies $\mathrm{G}^{\prime}(\mathrm{T}(\mathrm{a}), \mathrm{T}(\mathrm{x}), \mathrm{T}(\mathrm{y}))<\varepsilon$. A function $\mathrm{T}$ is G-continuous at $\mathrm{X}$ if and only if it is $\mathrm{G}-$ continuous at all $\mathrm{a} \in \mathrm{X}$.

Proposition: 2.3 (see [8])Let $(X, G)$ and $\left(X^{\prime}, G^{\prime}\right)$ are $G$-metric spaces. Then $T: X \rightarrow X^{\prime}$ is G-continious at $x \in X$ if and only if it is G-sequentially continuous at $x$; that is, whenever $\left(x_{n}\right)$ is G-convergent to $x,\left(T\left(x_{n}\right)\right)$ is $G-$ convergent to $\mathrm{T}(\mathrm{x})$.

Proposition: 2.4(see [8]) let $(\mathrm{X}, \mathrm{G})$ be a G-metric space. Then the function $\mathrm{G}(\mathrm{x}, \mathrm{y}, \mathrm{z})$ is jointly continuous in all three of its variable.

Definition: 2.5(see [8]) A G-metric space $(X, G)$ is called G-complete if every G-Cauchy sequence in $(X, G)$ is G-convergent in $(\mathrm{X}, \mathrm{G})$.

Definition: 2.6(see [8]) A G-metric space on $X$ is said to be symmetric if $G(x, y, y)=G(y, x, x)$ for all $x, y \in X$. Definition: 2.7Let $(X, \leq)$ be a partially ordered set and $T: X \rightarrow X$ be say that non-decreasing mapping if forx, $\mathrm{y} \in \mathrm{X}, \mathrm{x} \leq \mathrm{y} \Rightarrow \mathrm{Tx} \leq \mathrm{Ty}$.

The notion of weakly increasing mappings was introduced in by Altun and Simsek [14].

Definition 2.8(see [14]) Let $(X, \leq)$ be a partially ordered set. Two mappings T, S: $\rightarrow X$ are said to be weakly increasing if $\mathrm{Tx} \leq \mathrm{STx}$ and $\mathrm{Sx} \leq \mathrm{TSx}$ for allx $\in \mathrm{X}$.Two weakly increasing mappings need not be non-decreasing. Example: 2.1(see [14]) LetX $=\mathbb{R}^{+}$, endowed with the usual ordering. Let $\mathrm{T}, \mathrm{S}: \rightarrow \mathrm{X}$ defined by

$$
\begin{aligned}
\mathrm{Tx} & =\left\{\begin{array}{lr}
\mathrm{x}, & 0 \leq \mathrm{x} \leq 1, \\
0, & 1<\mathrm{x}<+\infty,
\end{array}\right. \\
\mathrm{Sx} & =\left\{\begin{array}{lr}
\sqrt{\mathrm{x}}, & 0 \leq \mathrm{x} \leq 1, \\
0, & 1<\mathrm{x}<+\infty .
\end{array}\right.
\end{aligned}
$$

Then $\mathrm{T}$ and $\mathrm{S}$ are weakly increasing mappings. Note that $\mathrm{T}$ and $\mathrm{S}$ are not non-decreasing.

\section{Main Results}

We will prove the following result:

Theorem: 3.1Let $(X, \leq)$ be a partially ordered set and suppose that there exists G-metric in $X$ such that $(X, G)$ is G-complete. Let $\mathrm{T}, \mathrm{S}: \mathrm{X} \rightarrow \mathrm{X}$ be two weakly increasing mappings with respect to $\leq$, satisfying the following conditions:

(3.1) $\quad G(T x, S x, S x) \leq g(G(x, y, y), G(x, T x, T x), G(y, S y, S y))$

(3.2) $\quad G(S x, T y, T y) \leq g(G(x, y, y), G(x, S x, S x), G(y, T y, T y))$

for all comparative $\mathrm{x}, \mathrm{y} \in \mathrm{X}$. where, $\mathrm{g} \in \mathcal{F}$. If $\mathrm{T}$ or $\mathrm{S}$ is $\mathrm{G}$-continuous, then $\mathrm{T}$ and $\mathrm{S}$ have a common fixed point $\mathrm{u}$ in $\mathrm{X}$.

Proof: Let $x_{0}$ be an arbitrary point in $X$. choose $x_{1} \in X$ such that $x_{1}=T x_{0}$. Again choose $x_{2} \in X$ such that $\mathrm{Sx}_{1}=\mathrm{x}_{2}$. Also choose $\mathrm{x}_{3} \in \mathrm{X}$ such that $\mathrm{x}_{3}=\mathrm{Tx}_{2}$. Continuing this fashion, we can construct a sequence in $\left\{\mathrm{x}_{\mathrm{n}}\right\}$ in $X$ such that $x_{2 n+1}=T_{2 n}, \forall n \in N \cup\{0\}$ and $x_{2 n+2}=S x_{2 n+1}, \forall n \in N \cup\{0\}$. Since $T$ and $S$ are weakly increasing with respect to $\leq$, we get:

$$
\mathrm{x}_{1}=\mathrm{Tx}_{0} \leq \mathrm{S}\left(\mathrm{Tx}_{0}\right)=\mathrm{Sx}_{1}=\mathrm{x}_{2} \leq \mathrm{T}\left(\mathrm{Sx}_{1}\right)=\mathrm{Tx}_{2}=\mathrm{x}_{3}
$$

$$
\leq \mathrm{S}\left(\mathrm{Tx}_{2}\right)=\mathrm{Sx}_{3}=\mathrm{x}_{4} \leq \cdots \cdots \cdots
$$

Form (3.1), we have

$$
\begin{aligned}
G\left(x_{2 n+1}, x_{2 n+2}, x_{2 n+2}\right) & =G\left(T x_{2 n}, S x_{2 n+1}, S x_{2 n+1}\right) \\
& \leq g\left(\begin{array}{c}
G\left(x_{2 n}, x_{2 n+1}, x_{2 n+1}\right), G\left(x_{2 n}, T x_{2 n}, T x_{2 n}\right), \\
G\left(x_{2 n+1}, S x_{2 n+1}, S x_{2 n+1}\right)
\end{array}\right) \\
& =g\left(\begin{array}{c}
G\left(x_{2 n}, x_{2 n+1}, x_{2 n+1}\right), G\left(x_{2 n}, x_{2 n+1}, x_{2 n+1}\right), \\
G\left(x_{2 n+1}, x_{2 n+2}, x_{2 n+2}\right)
\end{array}\right)
\end{aligned}
$$

Thus, by (g-2), we have

(3.4) $\quad G\left(x_{2 n+1}, x_{2 n+2}, x_{2 n+2}\right) \leq h G\left(x_{2 n}, x_{2 n+1}, x_{2 n+1}\right)$

Similarly, by (3.2), we have

$$
G\left(x_{2 n}, x_{2 n+1}, x_{2 n+1}\right)=G\left(S x_{2 n-1}, T x_{2 n}, T x_{2 n}\right)
$$


Thus, from (g-2), we obtain:

(3.5)

Therefore, by (1.4) and (1.5),

$$
\begin{gathered}
\leq g_{1}\left(\begin{array}{c}
G\left(x_{2 n-1}, x_{2 n}, x_{2 n}\right), G\left(x_{2 n-1}, S x_{2 n-1}, S x_{2 n-1}\right), \\
G\left(x_{2 n}, T x_{2 n}, T x_{2 n}\right)
\end{array}\right) \\
=g_{1}\left(\begin{array}{c}
G\left(x_{2 n-1}, x_{2 n}, x_{2 n}\right), G\left(x_{2 n-1}, x_{2 n}, x_{2 n}\right), \\
G\left(x_{2 n}, x_{2 n+1}, x_{2 n+1}\right)
\end{array}\right) \\
G\left(x_{2 n}, x_{2 n+1}, x_{2 n+1}\right) \leq h G\left(x_{2 n-1}, x_{2 n}, x_{2 n}\right) \\
G\left(x_{n}, x_{n+1}, x_{n+1}\right) \leq h G\left(x_{n-1}, x_{n}, x_{n}\right) \forall n \in N .
\end{gathered}
$$

If $x_{0}=x_{1}$, we get $G\left(x_{n}, x_{n+1}, x_{n+1}\right)=0$ for each $n \in N$. Hence $x_{n}=x_{0}$ for each $n \in N$. Therefore $\left\{x_{n}\right\}$ is $G$ Cauchy sequence in $X$. So without loss of generality, we assume that $x_{0} \neq x_{1}$. Let $m, n \in N$ withm $>n$. By axiom[G5] of the definition of G-metric space, we get:

$$
G\left(x_{n}, x_{m}, x_{m}\right) \leq G\left(x_{n}, x_{n+1}, x_{n+1}\right)+G\left(x_{n+1}, x_{n+2}, x_{n+2}\right)+\cdots \ldots+G\left(x_{m-1}, x_{m}, x_{m}\right)
$$

Using (3.6), we have

$$
\begin{aligned}
G\left(x_{n}, x_{m}, x_{m}\right) & \leq\left[h^{n}+h^{n+1}+\cdots \ldots .+h^{m-1}\right] G\left(x_{0}, x_{1}, x_{1}\right) \\
& \leq \frac{h^{n}}{1-h} G\left(x_{0}, x_{1}, x_{1}\right)
\end{aligned}
$$

On making limit $\mathrm{m}, \mathrm{n} \rightarrow \infty$ in (3.8), we get

$$
\lim _{m, n \rightarrow \infty} G\left(x_{n}, x_{m}, x_{m}\right)=0
$$

This implies that $\left\{x_{n}\right\}$ is G-Cauchy sequence in $(X, G)$ and so, since $(X, G)$ is G-complete; it converges to a point $u$ in $X$. Also the sub-sequences $\left(x_{2 n+1}\right)=\left(T_{2 n}\right)$ and $\left(x_{2 n+2}\right)=\left(\operatorname{Sx}_{2 n+1}\right)$ converge to $u$.

Further, the G-continuity of $\mathrm{T}$ implies

$$
\begin{aligned}
\mathrm{Tu} & =\mathrm{T}\left(\lim _{\mathrm{n} \rightarrow \infty} \mathrm{x}_{2 \mathrm{n}}\right)=\lim _{\mathrm{n} \rightarrow \infty} \mathrm{Tx}_{2 \mathrm{n}} \\
& =\lim _{\mathrm{n} \rightarrow \infty} \mathrm{x}_{2 \mathrm{n}+1}=\mathrm{u}
\end{aligned}
$$

And this proves that $\mathrm{u}$ is a fixed point of T. Now, we claim thatTu $=u$. Since $u \leq u$, by inequality (3.1), we have

$$
\begin{aligned}
\mathrm{G}(\mathrm{u}, \mathrm{Su}, \mathrm{Su}) & =\mathrm{G}(\mathrm{Tu}, \mathrm{Su}, \mathrm{Su}) \\
& \leq \mathrm{g}_{1}(\mathrm{G}(\mathrm{u}, \mathrm{u}, \mathrm{u}), \mathrm{G}(\mathrm{u}, \mathrm{Tu}, \mathrm{Tu}), \mathrm{G}(\mathrm{u}, \mathrm{Su}, \mathrm{Su})) \\
& =\mathrm{g}_{1}(0,0, \mathrm{G}(\mathrm{u}, \mathrm{Su}, \mathrm{Su})) \\
& =0 \text {, by property }(\mathrm{g}-2)
\end{aligned}
$$

That is, $\mathrm{Su}=\mathrm{u}$, which means that the point $\mathrm{u} \in \mathrm{X}$ is a common fixed point of $\mathrm{T}$ and $\mathrm{S}$. If $\mathrm{S}$ is $\mathrm{G}$-continuous. By similar argument as above we shows that $\mathrm{S}$ and $\mathrm{T}$ have a common fixed point. This finishes the proof.

In what fallows, we prove that Theorem 3.1 is still valid for $\mathrm{T}$ and $\mathrm{S}$, not necessarily continuous, assuming the following hypothesis in $\mathrm{X}$ :

(3.11) If $\left\{x_{n}\right\}$ is a non-decreasing sequence in $X$ such that $x_{n} \rightarrow x$, then $x=\sup \left\{x_{n}\right\}$, for all $n \in N$.

Theorem: 3.2 Let $(X, \leq)$ be a partially ordered set and suppose that there exists G-metric in $X$ such that $(X, G)$ is G-complete. Let $\mathrm{T}$ and $\mathrm{S}$ be two weakly increasing mappings with respect to $\leq$, satisfying the conditions (3.1) and (3.2). Assume that $X$ satisfies (3.11). Then $T$ and $S$ have a common fixed point $u$ in $X$.

Proof: Following the proof of Theorem 1, we only have to check $\mathrm{Tu}=\mathrm{Su}=\mathrm{u}$.

As $\left\{x_{n}\right\}$ is an increasing sequence in $X$ and $x_{n} \rightarrow u$. Thus $\left(x_{2 n}\right),\left(x_{2 n+1}\right),\left(\operatorname{Tx}_{2 n}\right)$ and $\left(\operatorname{Sx}_{2 n+1}\right)$ converge to $u$. since $X$ satisfies property (3.11), we get thatu $=\operatorname{Sup}\left\{x_{n}\right\}$, particularly, $x_{n} \leq u$ for all $n \in N$. Thus $x_{2 n}$ and $u$ are comparative. By (3.1), we have

(3.12) $\quad \mathrm{G}\left(\mathrm{Tx}_{2 n}, \mathrm{Su}, \mathrm{Su}\right) \leq \mathrm{g}\left(\mathrm{G}\left(\mathrm{x}_{2 \mathrm{n}}, \mathrm{u}, \mathrm{u}\right), \mathrm{G}\left(\mathrm{x}_{2 n}, \mathrm{Tx}_{2 n}, \mathrm{Tx}_{2 n}\right), \mathrm{G}(\mathrm{u}, \mathrm{Su}, \mathrm{Su})\right)$

On making limit $n \rightarrow+\infty$ in (3.12) and using the fact that $g$ and Gare continuous, by property (g-2), we obtain:

$$
\begin{aligned}
\mathrm{G}(\mathrm{u}, \mathrm{Su}, \mathrm{Su}) & \leq \mathrm{g}(0,0, \mathrm{G}(\mathrm{u}, \mathrm{Su}, \mathrm{Su})) \\
& =\mathrm{hG}(\mathrm{u}, \mathrm{Su}, \mathrm{Su})
\end{aligned}
$$

which means that $\mathrm{G}(\mathrm{u}, \mathrm{Su}, \mathrm{Su})=0$ that is, $\mathrm{u}=\mathrm{Su}$.

By similar argument, we may show thatu $=$ fu. This finishes the proof.

\section{References:}

[1]. Delbosco's, D. A Unified approach for all contractive mappings, Inst. Math.Univ. Torino, Report No. 19, 1981

[2]. Cho. Y. J., Fixed points for compatible mappings of type (A), Math. Japonica 38 (3), (1993), 497-508.

[3]. Constantin, A., Common Fixed Points of weakly Commuting mappings in 2-metric spaces, Math. Japonica 36 (3), (1991), 507-514.

[4]. Constantin, A., On Fixed Points in non-composite metric space, publ. Math. Debrecen 40 (3-4) (1992), 297-302.

[5]. E. S. Wolk, “Continuous convergence in partially ordered Sets,” General Topology and its Applications, Vol. 5, no. 3, pp. 221-234, 1975 .

[6]. B. Monjardet, Metries on partially ordered Sets-a Survej,” Dicrete Mathematics, Vol. 35, pp. 173-184, 1981. 
[7]. A. C. M. Ran and M. C. B. Recurings, "A fixed point theorems in partially ordered sets and some applications to matrix Mathematical Society, Vol. 132, no. 5, pp. 1435-1443, 2004.

[8]. Z. Mustafa and B. Sims, "A new approach to generalized metric spaces," Journal of nonlinear and Convex Analysis, Vol. 7, no. 2, pp. 289-297, 2006

[9] Z. Mustafa, W. Shatanawi, and M. Bataineh, "Existence of fixed point results in G-metric spaces". International Journal of mathematics and Mathematical Sciences, Vol. 2009, Article ID 283028, 10 pages, 2009.

[10] Z. Mustafa and B. Sims, "Some remarks concerning D-metric spaces" in proceeding of the International conference on Fixed Point Theory and Applications. Valencia (Spain), July (2003), pp. 189-198.

[11] Z. Mustafa, "A new structure for generalized metric spaces with applications to fixed point theory". Ph.D. thesis, University of Newcastle, Newcastle, UK, 2005.

[12] Z. Mustafa, H. Obiedat and F. Awawdeh, "Some fixed point theorem for mapping on complete G-metric spaces". Fixed point theory and Applications, Vol. 2008. Article Id 189870, 12 pages, 2008.

[13] Z. Mustafa and B. Sims, "Fixed point theorems for contractive mappings in complete G-metric spaces". Fixed point theory and Applications, Vol. 2009, Article Id 917175, 10 pages, 2009.

[14]. I. Attun and H. Simsek, "Some fixed point theorem on ordered metric spaces and application," Fixed point Theory and Applications, Vol. 2010, Article ID 621469, 17 Pages, 2010. 